\section{The ExTORTion of dentistry - is litigation and over-regulation best for our patients?}

\author{
A. C. L. Holden'
}
IN BRIEF
- Discusses why the tort law of negligence is not ideal for the resolution of claims of dental malpractice.
- Critically appraises whether both legal and regulatory actions against patients actually achieve a positive goal for them.
- Promotes the use of mediation in the management of disputes between dentists and patients as an alternative to traditional fitness-to-practise procedures.

\begin{abstract}
This article examines the current trends within UK dentistry for increased litigation and regulation. The law of tort when applied to dental negligence falls short of attaining justice for patients in a way which is focused on their best interests. It also has the effect of causing demoralisation and encouraging defensive practice. The introduction of a no-fault compensation scheme, such as that found in New Zealand, may be a solution to this issue, but this would come with questions around how it could be funded. The current system of high litigation and regulation, which shows no signs of relenting, seems to be in no-one's best interests. Therefore there is a real need to consider and propose alternatives that may break the continuum of increasing trends.
\end{abstract}

\section{INTRODUCTION}

For many years, the practise of dentists has been darkened by fear and concern regarding the possibility of litigation and regulatory sanction. Legal claims and complaints from the public and legal profession to the General Dental Council (GDC) regarding dental professionals have increased year on year for some time. ${ }^{1,2}$ As a profession, dentists are faced with vastly increased costs for indemnity insurance and most recently by a huge proposed increase in the annual retention fee (ARF), demanded by the GDC to cover the costs of these claims and complaints. Despite the recent reforms of civil litigation in relation to clinical negligence by Lord Justice Jackson, the amount of litigation is still rising, despite the predictions of both indemnifiers and the fears of lawyers. As well as this, the GDC has yet to act in curbing the numbers of claims from patients who are dissatisfied with their dental treatment. It is time that the downstream approach to managing patient dissatisfaction through arguably unhelpful fitness to practise processes and civil litigation is reconsidered. The reactionary sanctioning of dental professionals provides no benefit to patients and is more likely to result in practice that focuses upon professional risk management rather than a patient-centric approach.

General Dental Practitioner, Croft House Dental

Practice, Croft House, High Street, Maltby,

Rotherham, S66 8LH

Correspondence to: Alexander Holden

Email:aclholden@gmail.com

\section{Refereed Paper}

Accepted 2 September 2014

DOI: 10.1038/sj.bdj.2014.805

${ }^{\circ}$ British Dental Journal 2014; 217: 269-270
This increase in litigation and regulatory sanction, as well as being highly distressing and demoralising, also demonstrates that the current system of managing negligence claims and claims of misconduct are not working. This applies both to improving the experience for patients in gaining justice and also in creating an environment where clinicians can provide care that is in the interests of patients without the fear of legal or regulatory complaint. The increase in legal claims of recent times is not isolated to the practise of dentistry; other facets of medicine and other professions (especially the legal profession) have also experienced a rise in legal claims. Partly, this is due to a shift in cultural awareness and our transition towards a rights-based society. The law of tort (from the French meaning harm) has developed mainly to offer redress for victims of various torts, including negligence, battery and false imprisonment to name but a few. The other important aspect to tort law is to act as a deterrent to bad practice and behaviour. On the face of it, tort law may seem ideal as a solution for aggrieved patients but often it fails to deliver on either of these aims. This is because tort law has mainly developed in response to commercial disputes or disputes where the initial relationship between defendant and claimant was relatively simple.

\section{DOCTOR-PATIENT RELATIONSHIP}

The doctor-patient relationship belongs to an altogether different taxonomy and this means that tort may sometimes struggle to offer redress in these cases. When the judiciary are tasked with presiding over clinical negligence cases, unless they are medically or dentally trained, they cannot themselves determine whether the healthcare professional accused acted in a reasonable manner. In order to rule upon this, they are reliant upon expert opinion, utilising the Bolam test $^{3}$ for breach of duty and the question of 'but for' in the ascertaining of causation. All too often, this means that judgements are in effect decided by medical opinion, unless that opinion can be proved to be illogical. ${ }^{4}$ Because of this, tort law in relation to medicine comes under criticism for having a protectionist slant and that the law is doctormade rather than decided by the judiciary.

Tort also suffers because it fails to address the main reasons why patients seek legal redress or complain to a regulator. We hear a lot in the press and from anecdotes about the money-grabbing or vexatious complainant or claimant. While it is true that some complaints are born out of spite or from sotermed 'ambulance chasing' behaviour, the vast majority are seeking something else. The charity AvMA stated that the primary reason for patients to seek litigation is to gain an explanation for what has happened to them. ${ }^{5}$ The desire for financial recompense is not the main focus of the majority of patients who seek legal redress, only 30-39\% initially wanted financial compensation. ${ }^{6,7}$ As a by-product of litigation or a GDC fitnessto-practise investigation, a patient may be able to find out details of what happened. However, because this is not a primary objective of either process, a patient may not get the information they want or need. The other often-cited reason is to ensure that the same mistakes are not repeated and the organisation or profession involved learns from the 
incident. This is by no means guaranteed; there is nothing to enforce such change save for clinicians trying to either avoid similar litigation or making a conscious and independent choice to adopt new practice. There is no framework for analysing what lessons could and should be learnt as a result of civil actions against practitioners.

\section{WHAT IS THE ALTERNATIVE TO TORT?}

The failure of tort to appropriately address the real needs of patients suggests that an alternative is needed. Litigation is much maligned in the medical and dental professions for being seen to be unfair on clinicians who are just trying to help and do their job. The unsuitability and fickle nature of tort law is well illustrated by the case of Gregg $v$ S Scott; a man who lost the chance to recover from cancer due to negligent management and referral was denied remedy because his chance of survival was less than $50 \%$ initially, falling from $42 \%$ to $25 \%$. He lost something very real; his chance of survival was dramatically reduced but the Law Lords ruled against the recovery of damages because the initial chance of survival was below 50\%. How can it be right to decide justice based upon seemingly arbitrary statistics? One cannot fail to sympathise with patients in this situation. The reality is as McCall Smith and Merry state, 'In general, however blameless the doctor, the patient is even less to blame for the injury."

So what is the alternative to tort law? There is no medical negligence litigation in New Zealand. Instead, harmed patients may seek redress through the no-fault compensation scheme in operation there. This offers patients a set level of compensation for the sequelae of adverse events. The scheme is still based on a need to prove causation, which still prevents some from gaining access to justice. Despite this, the scheme does contribute to a greater number of patients being able to claim for medical harm, gaining compensation and justice than previously occurred before the introduction of the nofault model to dealing with claims. This should not be a deterrent to the introduction of such a scheme; the increase is explained by a greater number of patients having the ability to gain access to justice. Tort is hugely costly and potentially risky. After the event, insurance premiums are high and medical negligence claims are often rejected due to their complexity. This would leave a claimant in a worse situation should they fail in their claim than before they sought redress through the law. This contributes to a lack of social justice whereby some will not afford to be able to seek redress unless they can get a conditional fee arrangement (no-win-nofee) which may or may not be forthcoming.

\section{NO-FAULT SCHEME?}

The introduction of a no-fault scheme in England and Wales in relation to NHS medical treatment is unlikely in the near future due to the potential cost, despite the primary legislation for one having been introduced by the NHS Redress Act. ${ }^{9}$ It would not cover dental treatment in any event as it would be run by the NHS Litigation Authority which has nothing to do with primary care dentistry. Dentists' indemnity and registration fees are self-funded and so in essence the profession could collectively fund any legal or regulatory action that is taken against us. The establishment of a nofault scheme instead of the current culture of tort would theoretically serve dentistry well. The issue that would need to be addressed is whether cost would be a hindrance to implementing such a scheme. Indemnity is high for dentists practising in the UK; it shows no sign of decreasing. Potentially a no-fault scheme could be funded through the indemnifiers - in some ways this is encouraged already, with many indemnifiers preferring to fund aggrieved patients seeking specialist treatment directly rather than having to deal with legal claims and their associated costs.

Could a privately-run, redress scheme working on the principles of no-fault work in the UK for aggrieved dental patients? The idea of adopting such a scheme that would remove the need for such adversarial conflict between dentist and patient is interesting. However, perhaps a better solution would be to further encourage dentists to involve patients at the beginning of adverse events, with prompt referrals to specialists or remedial treatment, potentially being arranged through indemnifiers without leaving patients with a need to turn to legal help in getting redress. While there are issues surrounding the proposed duty of candour, the suggestion that patients need to be more involved in their treatments and promptly informed of any accidents or mistakes verges on common sense.

The GDC finds itself in receipt of an ever increasing number of claims against dentists and dental professionals. It sets its purpose as: 'Effective regulation of dental professionals enhances patient safety, improves the quality of care and helps ensure public confidence in dental regulation. 'We take action against those who do not meet our standards or who break the law by working without being registered.' Complaints to the GDC have increased by $110 \%$ between 2010 and $2014 .^{2}$ Just as tort struggles to fulfil the needs of patients, so does the GDC's fitness-to-practise process. Fitness-to-practise proceedings only offer sanctions against a dentist or DCP. There is no compensation available, nor is there any real guarantee that lessons will be learnt or that any preventive action will be taken by other dentists simply because dentists tend to operate in a rather isolated fashion. Patients may feel better that the conduct of their clinician has been sanctioned, but there is no real solution that might redress harm caused to a patient. The GDC has the power to order a dentist to undertake further training or they may impose conditions upon a dentist, but this does not help the patient who has been harmed in the first place. The Dental Complaints Service, which is independently run but funded by the GDC to allow patients to complain about private treatment, takes the role of a mediator between patient and dentist. This service is documented to be very successful at resolving disputes quickly and often to the satisfaction of both aggrieved patient and dentist. Perhaps this is the model that all but the most serious fitness-to-practise cases should take?

\section{QUESTION THE STATUS QUO}

The main message of this article is to question the current status quo. Dentistry is not alone as a profession in experiencing increased legal claims, but dentists do have the ability to deal with this in an independent manner as there is no need to conform to the policies of the NHS litigation authority. The profession is largely in control of the way it can deal with this increased claim culture. One thing seems to resonate: the current processes appear to do nothing for the profession and nothing for patients in resolving conflict that may arise as a result of dental treatment. To take back responsibility for this would allow far greater moves towards improving patient and professional satisfaction in the manner in which patient complaints, legal or regulatory, are dealt with.

1. Lewis R, Morris A, Oliphant K. Tort personal injury statistics: is there a compensation culture in the United Kingdom? Torts Law Journal 2006; 14: 158-175

2. Moyes W. Pendlebury lecture. London, Royal College of Surgeons of England: General Dental Council, 2014. Online lecture available at https://www. gdc-uk.org/Newsandpublications/viewfromthechair Documents/PENDLEBURY\%20LECTURE-William\%20 Moyes-June2014-FINAL.pdf (accessed July 2014).

3. Bolam v Friern Hospital Management Committee (1957) 2 All ER 118; (1957) 1 WLR 582.

4. Bolitho $v$ City and Hackney Health Authority (1997) 39 BMLR 1; (1998) 1 Lloyds Rep Med 26.

5. AvMA. Being open. Information available online at http: //www.avma.org.uk/pages/being_open.html (accessed September 2014).

6. Mulcahy L. Mediating medical negligence claims: an option for the future. The Stationary Office, 2000.

7. Vincent C, Young M, Phillips A. Why do people sue doctors? A study of patients and relatives taking legal action. Lancet 1994; 343: 1609-1613.

8. McCall Smith A, Merry A. Errors, medicine and the law. p 204. Cambridge: Cambridge University Press, 2001.

9. NHS Redress Act 2006. Act available online at http:// www.legislation.gov.uk/ukpga/2006/44/contents (accessed September 2014). 